First, they need to know what the potential local impacts will be at the scales of counties to cities. Some of this information could be gleaned by combining fine-resolution climate impact assessments with artificial intelligence for 'big data' analyses of weather extremes, health, property damage and other variables. Second, policymakers need to understand uncertainties in the ranges of probable climate impacts and responses. Even regions that are proactive in setting adaptation policies, such as California, lack information about the ever-changing risks of extreme warming, fires and rising seas. Research must be integrated across fields and stakeholders - urban planners, publichealth management, agriculture and ecosystem services. Adaptation strategies should be adjustable if impacts unfold differently. More planning and costing is needed around the worst-case outcomes.

Understand options for rapid response. Climate assessments must evaluate quick ways of lessening climate impacts, such as through reducing emissions of methane, soot (or black carbon) and HFCs. Per tonne, these three 'super pollutants' have 25 to thousands of times the impact of $\mathrm{CO}_{2}$. Their atmospheric lifetimes are short - in the range of weeks (for soot) to about a decade (for methane and HFCs). Slashing these pollutants would potentially halve the warming trend over the next 25 years $^{10}$.

There has been progress on this front. At

the Global Climate Action summit held in September in San Francisco, California, the United States Climate Alliance - a coalition of state governors representing $40 \%$ of the US population - issued a road map to reduce emissions of methane, HFCs and soot by $40-50 \%$ by 2030 (see go.nature.com/2ozhojc). The 2016 Kigali amendment to the Montreal

\section{"More planning and costing is} needed around the worst-case outcomes." Protocol, which will go into force by January 2019, is set to slash HFC emissions by $80 \%$ over the next 30 years.

Various climate engineering options should be on the table as an emergency response. If global conditions really deteriorate, we might be forced to extract large volumes of excess $\mathrm{CO}_{2}$ directly from the atmosphere. An even faster emergency response could be to inject aerosols into the atmosphere to lower the amount of solar radiation heating the planet, as air pollution does. This option is hugely controversial, and might have unintended consequences, such as altering rainfall patterns that lead to drying of the tropics. So research and planning are crucial, in case this option is needed. Until there is investment in testing and technical preparedness - today, there is almost none - the chances are high that the wrong kinds of climate-engineering scheme will be deployed by irresponsible parties who are uninformed by research ${ }^{11}$.

For decades, scientists and policymakers have framed the climate-policy debate in a simple way: scientists analyse long-term goals, and policymakers pretend to honour them. Those days are over. Serious climate policy must focus more on the near-term and on feasibility. It must consider the full range of options, even though some are uncomfortable and freighted with risk.

Yangyang $\mathrm{Xu}$ is an assistant professor of atmospheric sciences at Texas A\&M University, College Station, Texas, USA. Veerabhadran Ramanathan is professor of atmospheric and climate sciences and David G. Victor is professor of international relations at the University of California, San Diego, USA.

e-mail:david.victor@ucsd.edu

1. Intergovernmental Panel on Climate Change. Global Warming of $1.5^{\circ} \mathrm{C}$ (IPCC, 2018).

2. Le Quéré, C. et al. Earth Syst. Sci. Data 10, 405-448 (2018)

3. Smith, D. M. et al. Geophys. Res. Lett. https://doi. org/10.1029/2018GL079362 (2018)

4. Karplus, V. J., Zhang, S. \& Almond, D. Proc. Natl Acad. Sci. USA 115, 7004-7009 (2018).

5. Burnett, R. et al. Proc. Natl Acad. Sci. USA 115 , 9592-9597 (2018).

6. Salzmann, M. Sci. Adv. 2, e1501572 (2016).

7. Meehl, G. A., Hu, A. \& Teng, H. Nature Commun. 7 11718 (2016).

8. Chen, X. \& Tung, K.-K. Nature 559, 387-391 (2018).

9. Henley, B. J. \& King, A. D. Geophys. Res. Lett. 44, 4256-4262 (2017).

10.Xu, Y. \& Ramanathan, V. Proc. Natl Acad. Sci. USA 114, 10315-10323 (2017).

11.Victor, D. G. Oxford Rev. Econ. Pol. 24, 322-336 (2008).

\title{
Put more carbon in soils to meet Paris climate pledges
}

\section{Take these eight steps to make soils more resilient to drought, produce more food and store emissions, urge Cornelia Rumpel and colleagues.}

$\mathrm{S}$ oils are crucial to managing climate change. They contain two to three times more carbon than the atmosphere. Plants circulate carbon dioxide from the air to soils, and consume about onethird of the $\mathrm{CO}_{2}$ that humans produce. Of that, about $10-15 \%$ ends up in the earth.

Carbon is also essential for soil fertility and agriculture. Decomposing plants, bacteria, fungi and soil fauna, such as earthworms, release organic matter and nutrients for plant growth, including nitrogen and phosphorus. This gives structure to soil, making it resilient to erosion and able to hold water. Typically, organic matter accounts for a few per cent of the mass of soil near the surface.

Increasing the carbon content of the world's soils by just a few parts per thousand $(0.4 \%)$ each year would remove an amount of $\mathrm{CO}_{2}$ from the atmosphere equivalent to the fossil-fuel emissions of the European Union ${ }^{1}$ (around 3-4 gigatonnes (Gt)). It would also boost soil health: in studies across Africa, Asia and Latin America, increasing soil carbon by $0.4 \%$ each year enhanced crop yields by $1.3 \%$ (ref. 2 ).

Yet one-third of the world's soils are degraded $^{3}$. Poor farming practices, industry and urbanization take their toll. Throughout human history, $133 \mathrm{Gt}$ of carbon have been lost from soils, adding almost $500 \mathrm{Gt}$ of $\mathrm{CO}_{2}$ to the atmosphere ${ }^{4}$. As the amount of organic matter dwindles, soils face mounting damage from erosion, heatwaves and droughts - it is a vicious circle. In the worst cases, nothing can be grown. This is what happened in the 1930s 'dust bowl' in the central southern United States.

Improving soil carbon is now high on the political agenda. In 2015 at the Paris climate summit, France launched the 4p1000 initiative - to promote research and actions globally to increase soil carbon stocks by 4 parts per 1,000 per year. We are members of the scientific and technical committee for this initiative.

In November 2017 at the Bonn 


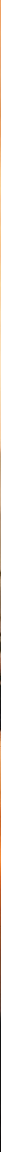

Air pollution in Sumatra in 2013 , where peatlands were burned to clear land for a palm-oil plantation.

climate conference in Germany, delegates established the Koronivia Joint Work on Agriculture programme. Tasked with helping farmers to reduce emissions and maintain food security in a changing climate, it will hold its first workshop this week at the annual summit of the United Nations Framework Convention on Climate Change (UNFCCC) in Katowice, Poland.

We call on countries involved in the Koronivia process to establish a body to monitor soil carbon in farmland, map changes to it and reclaim degraded areas. All involved should focus on the eight steps set out below.

\section{EIGHT STEPS}

The following practices would increase the amount of carbon held globally in soil:

Stop carbon loss. Protecting peatlands is the first priority for keeping existing carbon in the ground. These hold between $32 \%$ and $46 \%$ of all soil carbon (an estimated 500 $700 \mathrm{Gt}$ of approximately $1500 \mathrm{Gt}$ ) in an area about half the size of Brazil. Each year they take up about $1 \%$ of the global $\mathrm{CO}_{2}$ emissions generated by humans ${ }^{5}$.

Yet $10-20 \%$ of peatlands have been drained or burned and converted to agriculture, particularly in tropical areas. For example, fires used to clear land in maritime southeast Asia blanketed much of Indonesia in a toxic yellow haze during September and October 2015, emitting more $\mathrm{CO}_{2}$ per day than the whole of the European Union. Globally, such destruction is using up 1-2 $\mathrm{Gt} \mathrm{CO}_{2}$ per year of the remaining emissions budget necessary to stay within the Paris climate targets. To protect this resource, governments must ban burning of peatlands, stop their use in agriculture, or plan and enforce practices that preserve peat through continuous wet conditions.

Degraded mineral soils also need to be restored by controlling grazing, applying green manure or growing cover crops. Between 10 million and 60 million square kilometres of soils are degraded - up to $40 \%$ of the world's land area ${ }^{6}$. Restored, these could take up 9-19\% of global $\mathrm{CO}_{2}$ emissions for 25-50 years, at rates of 3-7 Gt of $\mathrm{CO}_{2}$ per year.

One global effort is making a start. The Bonn Challenge aims to improve $1.5 \mathrm{mil}$ lion $\mathrm{km}^{2}$ of degraded and deforested land by 2020 (and 3.5 million $\mathrm{km}^{2}$ by 2030) through conservation, recovery and sustainable management of forests and other ecosystems. It is overseen by the Global Partnership on Forest and Landscape Restoration, and is run by the International Union for Conservation of Nature.

Promote carbon uptake. Researchers need to establish a set of best practices for getting more carbon into soil. Proven techniques include making sure the soil is planted all year round, adding crop residues such as mulch and straw or compost, and minimizing tillage practices such as ploughing. In areas at high risk of erosion, contour farming and terracing should be implemented. Agroforestry systems, hedges and wetlands can increase biodiversity and soil carbon. Planting nitrogen-fixing plants such as beans, alfalfa and oilseed rape reduces the need for mineral fertilizers, which can release nitrous oxide, a greenhouse gas that is around 300 times more potent than $\mathrm{CO}_{2}$ (ref. 7).

Soils need regular inputs of organic matter. Competing demands for crop residues (also used as fodder) or dung (also used in cooking or heating) can limit what is available. Shortages of other soil nutrients might reduce the capacity of plants to produce enough organic matter to restore all soils.

Regional strategies for increasing soil carbon need to be developed, taking into account local soil types, climates, rates of climate change and socioeconomic contexts. These will favour particular plant species and restrict certain practices. For example, burning stubble or straw for land clearance should be prevented in Asia and South America. Similarly, slash and burn of tropical forests should be avoided in Africa. In Europe, reducing mineral fertilizers and implementing agroecological practices would be effective.

Monitor, report and verify impacts. Researchers and land managers need to track and evaluate interventions. Large-scale, 
long-term frequent monitoring is costly. It involves extensive field surveys that collect hundreds of samples per hectare, with laboratory analyses costing up to US $\$ 10$ per sample. And to yield sufficient georeferenced data to capture small changes in soil organic carbon over time, it must continue for at least 10 years. Obtaining access to private land is one challenge. Another is a lack of technical expertise and knowledge, especially in developing countries.

The Global Soil Laboratory Network (GLOSOLAN) is working to improve matters by harmonizing protocols and standards and setting up global training programmes in soil analysis. GLOSOLAN is part of the Global Soil Partnership run by the Food and Agriculture Organization of the United Nations.

Deploy technology. Advanced instruments make soil measurements cheaper, faster and more accurate. Portable infrared spectroscopes will soon be capable of tracking multiple chemical signatures in soil, including carbon, for less than $\$ 1$ per sample. Harmonized methodologies, verification standards and common guidelines will be needed for all these devices. Satellite imagery is also essential for scanning wide areas. Researchers should design automatic procedures and algorithms for assessing soil carbon content from space, or for predicting it from the characteristics of vegetation. These techniques should work whether soils are wet or dry, and for surfaces that are rough or smooth. They will require rigorous, ground-based verification.

Test strategies. Computer models and a network of field sites ${ }^{8}$ need to be developed to test the effectiveness of, say, avoiding ploughing. Farms should report their actions, verified by spot checks, field surveys or remote sensing. Data on soil types and meteorological variables will also need to be collected. Some open research databases exist: the Integrated Carbon Observation System measures exchanges of greenhouse gases across 120 experimental sites in Europe, for instance. But soil data need to be more transparent and accessible.

Involve communities. The public should be made more aware of the importance of soil organic carbon and of their ability to improve it on farms, in private gardens and public areas. Citizen-science approaches to collecting data, which are widely used in urban planning, for example, should be extended to soils. A good example is the earthworm population survey conducted by farmers across 1,300 hectares in the United Kingdom, which helped to assess farmland biodiversity (see also J. L. Stroud Nature 562, 344; 2018).

A global, open, online platform to collect and share soil carbon data needs to be established. It could be based on GlobalSoilMap, which was set up by scientists in 2009.

Basing it on a widely used technology, such as a geographic information system (GIS), would broaden its reach and reduce the need for training. Such open platforms will be important in developing countries, where access to resources is limited.

Coordinate policies. Political frameworks covering soils and climate change should work together. These include parties involved in SDG15 - the UN Sustainable Development Goal that seeks to halt and reverse land degradation by 2030 - and the UN Convention to Combat Desertification, which has targets and funding for stopping land degradation and managing land sustainably. Scientists should help countries to integrate soil carbon goals in their pledged emissions cuts to the Paris agreement. And the Koronivia programme should develop complementary targets for storing soil carbon.

Targets and policies will be needed to reform agricultural practices worldwide, which will take decades. Farmers will need incentives to change their methods. Finan-

"Soils face mounting damage from erosion, cial compensation could be given to cover costs and heatwaves and droughts."

risks, for example. Researchers need a better understanding of geographical priorities, such as hotspots that combine harsh climates and vulnerable populations.

Provide support. Policymakers should include soil carbon in emissions-trading schemes and carbon taxes. This will be harder than schemes for $\mathrm{CO}_{2}$ because soil carbon is transient, unevenly distributed and harder to measure. Crop insurance and other services can offer premiums to farmers who have improved soil carbon. Carbon credits or discounts could be given for lands that are at risk of soil-carbon loss ${ }^{9}$.

Some governments have begun to act. India has distributed soil-health cards to 100 million farmers. These explain how to test soil for nutrients and choose fertilizers. China has banned agricultural fires and subsidizes farmers who return residues to fields ${ }^{10}$. The United States compensates farmers who remove cropland from production and increase areas of carbon-rich grasslands.

Development banks and investors should create global investment funds to support practices that improve soil carbon. These could be similar to the Moringa fund, which targets agroforestry projects in Latin America and sub-Saharan Africa.

\section{WHAT NEXT?}

First, researchers, policymakers and land managers need to recognize that increasing soil carbon stocks and protecting carbon-rich soils is crucial for achieving the Paris climate targets and SDGs. Policyfocused organizations should convene a joint forum to coordinate action. This could be hosted by the $4 \mathrm{p} 1000$ initiative. Neighbouring countries should exchange experiences, develop common management strategies and make joint decisions on climate-change mitigation, adaptation and land degradation.

Second, international funding agencies should set up a pool of several million dollars to address urgent research gaps, such as those identified by the $4 \mathrm{p} 1000$ initiative. These include: estimating the potential for soil carbon storage; developing targets and management practices; designing monitoring, reporting and verification strategies; and understanding basic soil-plant processes.

As the Koronivia summit begins, governments must pledge funds to bring together soil experts, donors and policymakers to act on soil carbon storage.

Cornelia Rumpel is chair of the 4p1000 initiative's scientific and technical committee and director of research at the CNRS Institute of Ecology and Environmental Sciences, ThivervalGrignon, France. Farshad Amiraslani is deputy dean of academic affairs, Faculty of Geography, University of Tehran, Iran. Lydie-Stella Koutika is a senior researcher and deputy director of the Research Center on Productivity and Sustainability of Industrial Plantations (CRDPI), PointeNoire, Republic of the Congo. Pete Smith is professor of soils and global change, University of Aberdeen, UK. David Whitehead is a plant and soil scientist at Manaaki Whenua - Landcare Research, Lincoln, New Zealand. Eva Wollenberg is a research professor and flagship leader in the CGIAR Research Program CCAFS, University of Vermont, Burlington, USA. e-mail:cornelia.rumpel@inra.fr

1. Chabbi, A. et al. Nature Clim. Change 7, 307-309 (2017).

2. Soussana, J.-F. et al. Soil Tillage Res. https://doi. org/10.1016/j.still.2017.12.002 (2017).

3. Food and Agriculture Organization of the United Nations and Intergovernmental Technical Panel on Soils. Status of the World's Soil Resources Main Report (FAO \& ITPS, 2015).

4. Sanderman, J., Hengl, T. \& Fiske G. J. Proc. Natl Acad. Sci. USA 114, 9575-9580 (2017).

5. Leifeld, J. \& Menichetti, L. Nature Commun. 9 , 1071 (2018).

6. Gibbs, H. K. \& Salmon, J. M. Appl. Geogr. 57, 12-21 (2015).

7. IPCC. Guidelines for National Greenhouse Gas Inventories. Volume 4: Agriculture, Forestry and Other Land Use (IPCC, 2006).

8. Smith, P. et al. Glob. Change Biol. 18, 2089-2101 (2012).

9. Thamo, T. \& Pannell, D. J. Clim. Pol. 16, 973-992 (2016).

10.Zhao, Y. et al. Proc. Natl Acad. Sci. USA 115 4045-4050 (2018)

A list of co-signatories accompanies this article online (see go.nature.com/2skatbf). 